Article

\title{
Subcritical Fluid Chromatography at Sub-Ambient Temperatures for the Chiral Resolution of Ketamine Metabolites with Rapid-Onset Antidepressant Effects
}

\author{
Robert K. Hofstetter ${ }^{1, *(D)}$, Felix Potlitz ${ }^{1}$, Lukas Schulig ${ }^{1}\left(\mathbb{D}\right.$, Simon Kim ${ }^{2,3}{ }^{(D}$, Mahmoud Hasan ${ }^{4}$ \\ and Andreas Link 1,*(D) \\ 1 Pharmaceutical and Medicinal Chemistry, Institute of Pharmacy, Friedrich-Ludwig-Jahn-Str. 17, \\ 17489 Greifswald, Germany; felix.potlitz@gmail.com (F.P.); lukas.schulig@uni-greifswald.de (L.S.) \\ 2 Department of Trauma, Reconstructive Surgery and Rehabilitation Medicine, University Medicine \\ Greifswald, Ferdinand-Sauerbruch-Straße, 17475 Greifswald, Germany; kims@uni-greifswald.de \\ 3 Leibniz Institute for Plasma Science and Technology (INP Greifswald), Felix-Hausdorff-Straße 2, \\ 17489 Greifswald, Germany \\ 4 Department of Clinical Pharmacology, Center of Drug Absorption and Transport (C_DAT), \\ University Medicine Greifswald, 17475 Greifswald, Germany; hasanm@uni-greifswald.de \\ * Correspondence: hofstetter@uni-greifswald.de (R.K.H.); link@uni-greifswald.de (A.L.); \\ Tel.: +49-3834-420-4842 (R.K.H.)
}

Academic Editor: Toshitaka Funazukuri

Received: 30 April 2019; Accepted: 17 May 2019; Published: 19 May 2019

\begin{abstract}
Chiral metabolites of ketamine exerting rapid-onset yet sustained antidepressant effects may be marketed directly in the future, but require chemo- and enantio-selective chromatographic methods for quality assurance and control. The chromatographic behavior of $S$-/R-ketamine, $S$-/R-norketamine, $S$-/R-dehydronorketamine, and $(2 R, 6 R)-/(2 S, 6 S)$-hydroxynorketamine in supercritical fluid chromatography (SFC) was investigated computationally and experimentally with the aim of identifying problematic pairs of enantiomers and parameters for chiral resolution. Retention on three different polysaccharide-based chiral stationary phases (Lux Amylose-2, i-Amylose-3, and i-Cellulose-5) provided new information on the significance of halogen atoms as halogen bond donors and hydrogen bond acceptors for enantioselectivity, which could be corroborated in silico by molecular docking studies. Modifiers inversely affected enantioselectivity and retention. Methanol yielded lower run times but superior chiral resolution compared to 2-propanol. Lower temperatures than those conventionally screened did not impair phase homogeneity but improved enantioresolution, at no cost to reproducibility. Thus, sub-ambient temperature subcritical fluid chromatography (SubFC), essentially low-temperature HPLC with subcritical $\mathrm{CO}_{2}$, was applied. The optimization of the SubFC method facilitated the chiral separation of ketamine and its metabolites, which was applied in combination with direct injection and online supercritical fluid extraction to determine the purity of pharmaceutical ketamine formulations for proof of concept.
\end{abstract}

Keywords: supercritical $\mathrm{CO}_{2}$; sub-ambient temperature; subcritical fluid chromatography; chiral resolution; immobilized; coated; chiral stationary phase; ketamine; metabolites; depression

\section{Introduction}

On 5 March 2019, ketamine (K) was approved by the FDA for treatment-resistant depression [1]. Unique in its mechanism of action and different from monoaminergic modulators, which alleviate depressive systems within 6-8 weeks and in only about $2 / 3$ of patients, $\mathrm{K}$ exerts rapid onset (within hours) yet sustained (one week and more) antidepressant effects, even in patients suffering from treatment-refractory depression [2]. Placebo-controlled studies suggest that the sub-anesthetic infusion 
of rac-K lowers suicidal ideation in patients suffering from bipolar depression to a greater degree than midazolam (used to address functional unblinding due to dissociative effects associated with verum administration), and demonstrated memory improvement and pre- to post-infusion decrease in serum brain-derived neurotrophic factor (BDNF) as promising biomarkers [3].

However, rac-K infusion is known to induce anxiety, which appears to be associated with higher non-responder rates (up to $45 \%$ ), defined as a less than $50 \%$ reduction on the Montgomery-Asberg Depression Rating Scale (MADRS) [4]. Euphoric and dissociative effects, on the other hand, increase abuse liability of $\mathrm{K}$, and although actual prevalence is not known, the incidence of recreational use among young adults is estimated to be as high as $4.5 \%$, which might include attempts at self-directed therapy [5].

The side effects and abuse liability associated with the parent drug have motivated the pursuit of K-like alternatives such as enantio-pure, sustained-release or active metabolite formulations in order to circumvent the current limitations placed on antidepressant therapy with $S$-K, which is available only for supervised administration at certified health care providers, and $r a c-K$, the off-label infusion of which is restricted to in-patients [6-8]. Regrettably, the nature and precise mechanism of action responsible for rapid-onset yet sustained antidepressant effects is still being debated [9].

Both $R$ - and $S$-K exert anesthetic effects by the non-competitive antagonism of glutamatergic $N$-methyl-D-aspartate receptors (NMDARs), with the $S$-enantiomer being approximately 3-4-fold more potent than the R-enantiomer. While the NMDAR hypothesis therefore predicts greater efficacy of $S-K$ as well as similar effects for non-K NMDAR subtype inhibitors, antidepressant-predictive animal models have indicated $R-\mathrm{K}$ to be the more potent antidepressant [10].

The identification of metabolites with distinctive pharmacodynamics has provided alternative hypotheses to $\mathrm{K}^{\prime}$ s mechanism of antidepressant action: demethylation yields $R$ - and $S$-norketamine $(R-/ S-N K)$, which may undergo oxidation to yield unsaturated $R$ - and $S$-dehydronorketamine $(R-/ S$-DHNK) and hydroxylated $(2 R, 6 R)$ - and $(2 S, 6 S)$-hydroxynorketamine (RR-/SS-HNK). The local blockade of NMDAR at the anti-reward center by K [11] or S-NK [12] may account for rapid-onset antidepressant effects, whereas synaptogenesis or BDNF modulation could exert long-term antidepressant effects [13]. RR-HNK, on the other hand, was shown to induce antidepressant effects through early and sustained activation of $\alpha$-amino-3-hydroxy-5-methyl-4-isoxazole propionic acid receptors (AMPARs) at levels insufficient for NMDAR inhibition [14], but may converge on the same downstream pathways, including BDNF modulation [15].

Interestingly, pharmaceutical formulations of these metabolites alleviated the detrimental effects associated with $\mathrm{K}$ administration in animal studies, as the parent drug rac-K is largely responsible for dissociative side effects and abuse potential [2].

The necessity of enantio- and chemo-selective determination methods for the pharmaceutical quality control of individual metabolite formulations is clear from the striking differences and eudysmic ratios between $\mathrm{K}, \mathrm{NK}, \mathrm{DHNK}$, and $\mathrm{HNK}$.

Although HPLC has been the workhorse of industrial-scale quality control, supercritical fluid chromatography (SFC) has begun to encroach on quality assurance territory as a sustainable [16] and notably more cost-effective alternative to conventional chromatography [17]. The use of supercritical $\mathrm{CO}_{2}\left(\mathrm{scCO}_{2}\right)$ as a hexane-like mobile phase is accompanied by beneficial physical attributes (high mass transfer, high diffusivity, low viscosity), which favors the rapid separation of complex mixtures even at conditions below the critical point (subcritical or enhanced fluidity) [18], and therefore has been used for the separation of metabolites of $\mathrm{K}$ from urine [19].

The aim of this study was to identify and optimize the parameters responsible for the enantioseparation of $\mathrm{K}$, as this racemate proved the most challenging to resolve on polysaccharide-based chiral stationary phases (CSPs). The choice of column and modifier were identified as major determinants while additives, pressure, and flow rate modulation had only minor effects on chiral resolution. Temperatures below the range conventionally screened provided a modest but essential 
improvement in selectivity over traditional SFC, which enabled the quality control of antidepressant rac-K and metabolite formulations.

\section{Results}

\subsection{Stationary Phase Screening}

We previously reported on the challenges associated with the HPLC bioanalysis of ketamine metabolites, which entailed one achiral C18-phase $\left(X_{\text {Terra }} \mathrm{MS}^{\circledR}\right)$ and two CSPs that were based on protein (Chiral-AGP ${ }^{\circledR}$ for $\mathrm{K}, \mathrm{NK}$ and DHNK) and polysaccharides (Lux ${ }^{\circledR}$ Amylose-2 for HNK) [20]. When operated in SFC mode, the same polysaccharide-based CSP afforded more versatility, as it enantioselectively resolved all metabolites but the parent drug $(K)$, which could not be fully separated even after optimization [19]. The development of immobilized CSPs in which the chiral selector is chemically bonded to the $\mathrm{SiO}_{2}$-particles has expanded physico-chemical compatibility [21] and in some cases provided additional selectivity and robustness for chiral separations [22]. In order to improve the resolution of $r a c-K$, three chlorinated CSPs that differed in chemical modification and polysaccharide backbone were compared. Employing the parameters shown in supplementary information Figure S1, Lux Amylose-2 [coated tris(3-chloro-5-methylphenylcarbamate)amylose], i-Amylose-3 [immobilized tris(3-chloro-5-methylphenylcarbamate)amylose] and i-Cellulose-5 [tris(3,5-dichlorophenylcarbamate)cellulose] were included in the initial column scouting (Figure 1a).

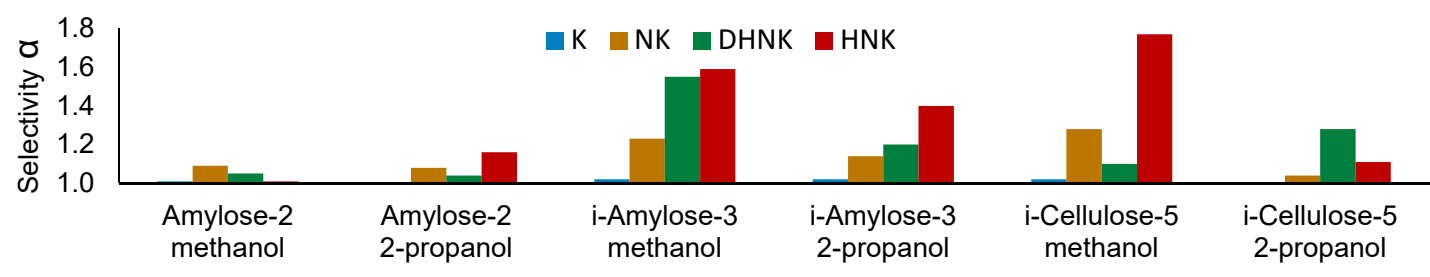

(a)

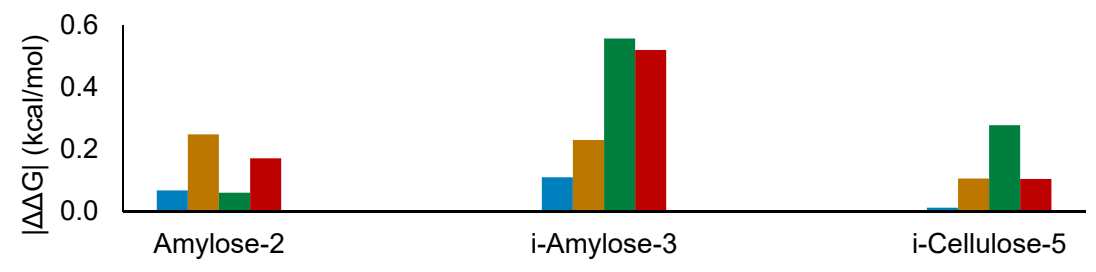

(b)

Figure 1. (a) Experimental screening for selectivity $(\alpha)$ on three chlorinated polysaccharide stationary phases for ketamine (K), norketamine (NK), dehydronorketamine (DHNK), and hydroxynorketamine (HNK), using supercritical $\mathrm{CO}_{2}\left(\mathrm{scCO}_{2}\right)$ modified by methanol or 2-propanol. (b) Calculated $|\Delta \Delta \mathrm{GG}|$-values (described in Section 2.2) enable the prediction of enantioseparation and aid the explanation of experimental results.

The screening verified earlier observations of higher enantioselectivity $(\alpha)$ for the separation of demethylated metabolites NK, DHNK and HNK compared to the parent drug K. In comparison to coated amylose-2, however, immobilized i-Amylose- 3 and i-Cellulose-5 exhibited higher chiral recognition, particularly when methanol was used. The highest $\alpha$ values were obtained for the hydroxylation product HNK, which was also separated on Amylose-2 but required the modifier 2-propanol. Albeit providing higher elution strength, the use of methanol as a modifier provided higher $\alpha$ on immobilized CSPs for most analytes, possibly due to conformational stabilization, and was therefore used in combination with i-Amylose-3 during further method development. 


\subsection{Molecular Modelling Studies}

Computational methods were utilized to investigate differences in the three-dimensional structure of the column polymers and possible interactions of the chiral recognition mechanism at the atomistic level by molecular docking.

In contrast to ligand-receptor interaction, there is no specific binding site for ligands on the polymer surface and the fluctuation between bound and unbound states is much larger. It is therefore hardly possible to calculate accurate quantitative energy contribution using molecular docking, even if solvent effects are taken into account. Nevertheless, it is a valuable tool to predict qualitative assertions and possible interaction with the polymer, as previously published in literature [23]. To gain a deeper understanding of the dynamic processes and the solvent effects, large scale molecular dynamics simulations will be a part of future work.

We prepared the three-dimensional structure of the three column types as hexamers and both enantiomers for all ligands according to the description in the Methods section. By using a blind docking approach, 25 docking poses were obtained and sorted by binding free energy to create a representative set of possible interaction sites. The main types of interactions are hydrogen bonds (donor/acceptor, including halogen acceptors), $\pi-\pi$, halogen, and $\mathrm{CH}-\pi$ bonds (Figure $2 \mathrm{a}-\mathrm{d}$ ).

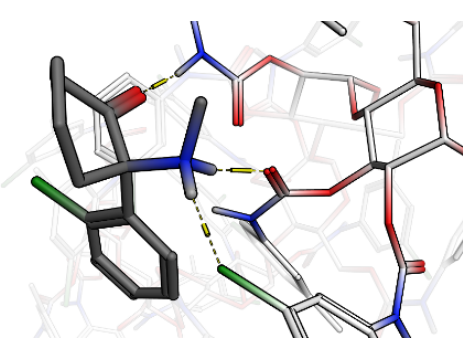

(a)

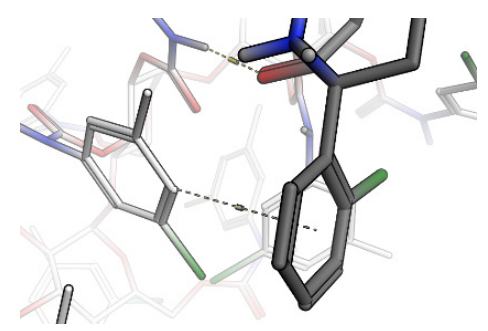

(c)

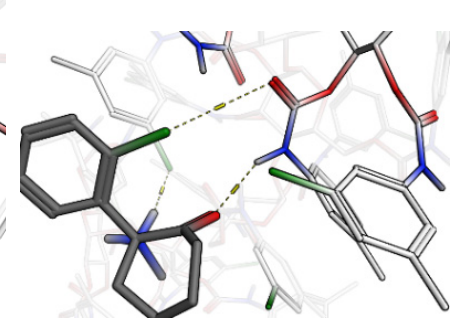

(b)

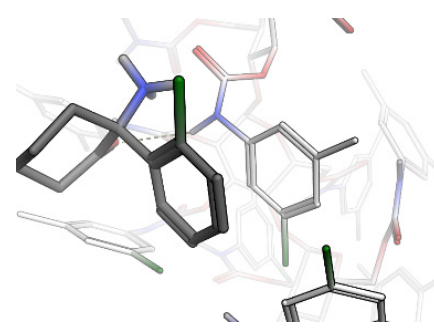

(d)

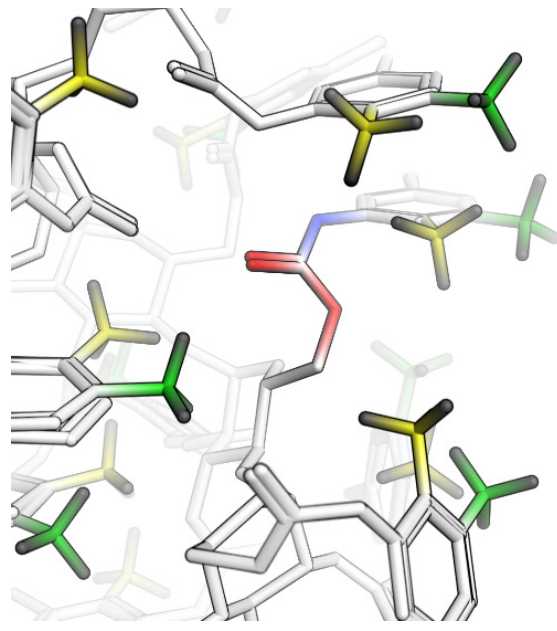

(e)

Figure 2. Representative poses of $R / S$-ketamine to depict possible interaction types: (a) Hydrogen bonding including halogen acceptors, (b) halogen bonds, (c) $\mathrm{CH}-\pi$ bonds and (d) $\pi-\pi$ interaction. (e) Superposition of Amylose-2 and i-Amylose-3 with methyl groups colored in yellow and green, respectively. The substituents in position 2 of the benzene ring sterically restrict access to the carbamate for hydrogen bonding.

In Table 1, the energy differences for the highest docking score between the two enantiomers $|\Delta \Delta \mathrm{G}|$ were calculated in order to predict chiral recognition on all three modified polysaccharide-based CSPs. As illustrated in Figure 1b, higher $|\Delta \Delta G|$ values are in good agreement with the experimentally determined enantioselectivity $\alpha$.

Since the only substitutional difference between Amylose-2 and i-Amylose- 3 is the position of the methyl group attached to a phenyl carbamate, we flexibly aligned both oligomers to get a better understanding of how this affects the three-dimensional structure. As shown in Figure 2e, the methyl groups of Amylose-2 (colored in yellow) sterically restrict accessibility to the carbamate (colored by atom), and thus prevent possible hydrogen or halogen bonding. To further investigate these interactions relating to chiral recognition, $R R$-HNK and SS-HNK were docked into the same site on 
i-Amylose-3, as it was known from experimental data which enantiomer had the higher residence time and HNK also had the highest enantioselectivity value on this phase.

Table 1. Calculated $|\Delta \Delta \mathrm{G}|$ and observed enantioseparation $\alpha$ using methanol ${ }^{1}$ or 2 -propanol ${ }^{2}$ as a modifier.

\begin{tabular}{|c|c|c|c|c|c|c|c|c|c|}
\hline \multirow{2}{*}{ Analyte } & \multicolumn{3}{|c|}{ Amylose-2 } & \multicolumn{3}{|c|}{ i-Amylose-3 } & \multicolumn{3}{|c|}{ i-Cellulose-5 } \\
\hline & $|\Delta \Delta \mathrm{G}|(\mathrm{kcal} / \mathrm{mol})$ & $\alpha^{1}$ & $\alpha^{2}$ & $|\Delta \Delta \mathrm{G}|(\mathrm{kcal} / \mathrm{mol})$ & $\alpha^{1}$ & $\alpha^{2}$ & $|\Delta \Delta \mathrm{G}|(\mathrm{kcal} / \mathrm{mol})$ & $\alpha^{1}$ & $\alpha^{2}$ \\
\hline K & 0.07 & 1.01 & 1.00 & 0.11 & 1.02 & 1.02 & 0.01 & 1.02 & 1.00 \\
\hline NK & 0.25 & 1.09 & 1.08 & 0.23 & 1.23 & 1.14 & 0.10 & 1.28 & 1.04 \\
\hline DHNK & 0.06 & 1.05 & 1.04 & 0.56 & 1.55 & 1.20 & 0.28 & 1.10 & 1.28 \\
\hline HNK & 0.17 & 1.01 & 1.16 & 0.52 & 1.59 & 1.40 & 0.10 & 1.77 & 1.11 \\
\hline
\end{tabular}

The final docking poses are shown in Figure 3. The RR-enantiomer is buried deeper in the oligomer surface while maintaining strong hydrogen bonding between the carbonyl and hydroxyl groups. Two additional hydrogen bonds are possible between the primary amino group and the chlorine substituents acting as acceptor atoms. As opposed to the SS-enantiomer, all hydrogen bond donors of the RR-HNK are saturated and not available for interactions with carbon dioxide (Figure 3). Chiral recognition appears to be based on the ability of one enantiomer to form stronger hydrogen bond networks with the stationary phase than its counterpart.

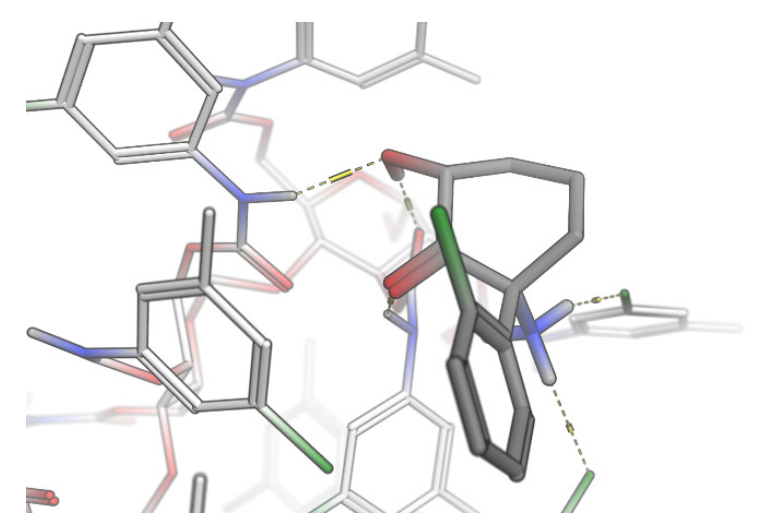

(a)

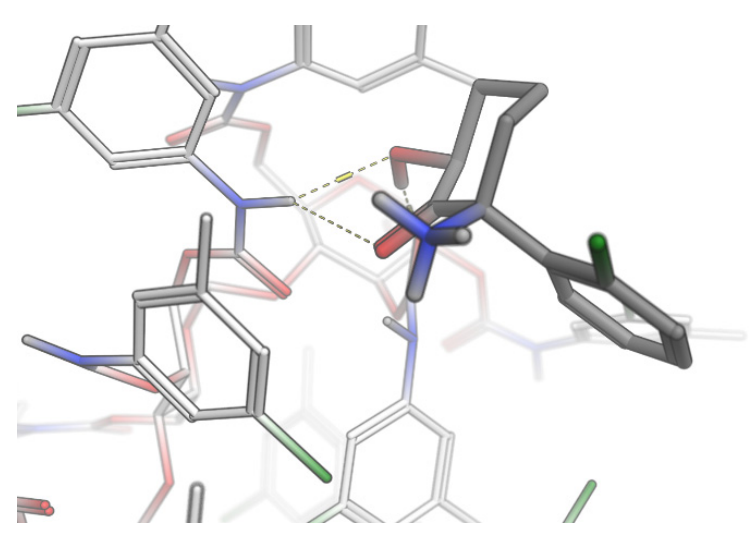

(b)

Figure 3. Docking poses of RR-HNK (a) and SS-HNK (b) at a defined binding site. The three-dimensional geometry of the $R R$-enantiomer permits a larger hydrogen bonding network, stronger hydrophobic interactions and therefore extended residence time. $(|\Delta \Delta \mathrm{G}|=2.1 \mathrm{kcal} / \mathrm{mol})$.

\subsection{Effects of Elution Mode}

The miscibility of $\mathrm{scCO}_{2}$ with polar co-solvents (modifiers) can be exploited to adjust mobile phase solvation strength. The critical point of such mixtures is generally beyond the pressure and temperature capacities of commercially available platforms, while the favorable fluid characteristics are retained and thus the term SFC is used for both super- (pure $\mathrm{scCO}_{2}$ ) and subcritical (modified scCO $\mathrm{C}_{2}$ ) mobile phase compositions containing more $\mathrm{CO}_{2}$ than modifier (as expressed by volumetric control) [24]. Because this terminology has its obvious flaws, Otsubo et al. avoid the term SFC for low-temperature HPLC using pure liquid carbon dioxide as the mobile phase in subcritical state [25]. The expansion of modifier use has led to the development of 'enhanced-fluidity liquid chromatography' (EFLC), where mobile phase proportions are switched (modifier $>\mathrm{scCO}_{2}$ ) to allow for the separation of analytes as polar as proteins, nucleosides, and sugars [26-28]. Since elution patterns may vary between SFC, non-polar HPLC with pure $\mathrm{CO}_{2}$, EFLC [29], and polar organic HPLC (100\% polar eluent) [30], isocratic elution with different $\mathrm{CO}_{2} /$ methanol ratios was used to study the effects of elution modes on ketamine metabolites and to identify the most promising mode for enantioseparation (Table 2). 
Table 2. Retention times (Rt) and factors ( $\mathrm{k}$ ) of the first eluted enantiomer and enantioseparation $\alpha$ of the racemates for ketamine (K), norketamine (NK), dehydronorketamine (DHNK) and hydroxynorketamine (HNK) at different ratios of co-solvent B (methanol) and flow rates (FR) on Lux i-Amylose-3.

\begin{tabular}{|c|c|c|c|c|c|c|c|c|c|c|c|c|c|c|c|}
\hline \multirow[t]{2}{*}{ Mode } & \multirow{2}{*}{$\begin{array}{c}B \\
(\%)\end{array}$} & \multirow{2}{*}{$\begin{array}{c}\text { FR } \\
(\mathrm{mL} / \mathrm{min})\end{array}$} & \multirow{2}{*}{$\begin{array}{c}\mathrm{t}_{0} \\
(\mathrm{~min})\end{array}$} & \multicolumn{3}{|c|}{$\bar{K}$} & \multicolumn{3}{|c|}{ NK } & \multicolumn{3}{|c|}{ DHNK } & \multicolumn{3}{|c|}{ HNK } \\
\hline & & & & $\mathbf{R t}^{1}$ & $\mathbf{k}$ & $\alpha$ & $\mathbf{R t}^{1}$ & $\mathbf{k}$ & $\alpha$ & $\mathbf{R t}^{1}$ & $\mathbf{k}$ & $\alpha$ & $R t^{1}$ & $\mathbf{k}$ & $\alpha$ \\
\hline \multirow[t]{4}{*}{ SFC } & 5 & 2.5 & 0.23 & 4.98 & 23.1 & 1.1 & 4.76 & 49.8 & 2.5 & 4.66 & 49.7 & 2.6 & 8.27 & 73.4 & 2.1 \\
\hline & 10 & 2.0 & 0.28 & 3.38 & 11.2 & 1.0 & 3.19 & 24.6 & 2.3 & 3.10 & 24.1 & 2.4 & 4.57 & 40.9 & 2.6 \\
\hline & 20 & 1.5 & 0.37 & 2.10 & 4.6 & 1.0 & 2.12 & 11.5 & 2.5 & 2.01 & 10.9 & 2.5 & 2.73 & 16.1 & 2.5 \\
\hline & 40 & 1.0 & 0.61 & 1.71 & 1.8 & 1.0 & 1.72 & 3.2 & 1.8 & 1.77 & 3.8 & 2.0 & 1.77 & 3.6 & 1.9 \\
\hline \multirow[t]{2}{*}{ EFLC } & 60 & 0.6 & 0.90 & 1.40 & 0.6 & 1.0 & 1.39 & 0.8 & 1.4 & 1.61 & 1.2 & 1.5 & 1.41 & 0.8 & 1.5 \\
\hline & 80 & 0.5 & 1.13 & 1.38 & 0.2 & 1.0 & 1.39 & 0.3 & 1.3 & 1.45 & 0.4 & 1.3 & 1.38 & 0.2 & 1.1 \\
\hline HPLC & 100 & 0.4 & 1.32 & 2.96 & 1.2 & 1.0 & 3.08 & 2.5 & 1.9 & 2.53 & 1.7 & 1.9 & 2.42 & 1.5 & 1.8 \\
\hline
\end{tabular}

In the presence of $\mathrm{scCO}_{2}$ (SFC, EFLC), rising modifier percentages increased the elution strength, which led to a decrease in retention for all analytes. Transition to HPLC, however, was associated with a trend reversal (higher retention/resolution at $100 \%$ compared to $60 \%$ methanol), leading to an apparent retention minimum within EFLC at 80\% (Figure 4). Interestingly, the transition from SFC to EFLC was accompanied by a reversal of elution order: in SFC mode, $\mathrm{K}$ and NK eluted first and HNK last (K $\approx$ NK $>$ DHNK > HNK); in EFLC mode, the retention of HNK began to fall below that of NK and DHNK, most likely due to the increase in hydrogen bond availability in the mobile phase (hydroxyl group of methanol) as this type of interaction was found to dominate retention and chiral recognition of HNK on Lux i-Amylose-3 (Figures 2a and 3). Since K was deemed the most challenging target racemate, further efforts focused on the SFC mode at low modifier gradients, as the isocratic screening yielded the highest $\alpha$ value for $\mathrm{K}$ at $5 \%$ methanol.

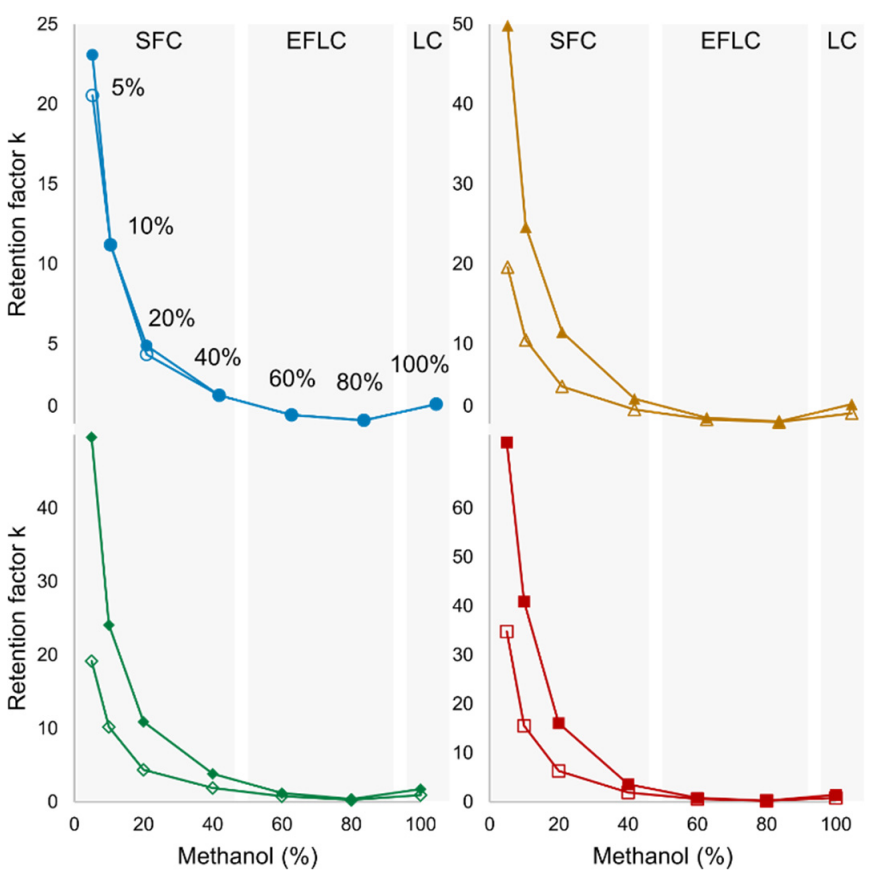

(a)

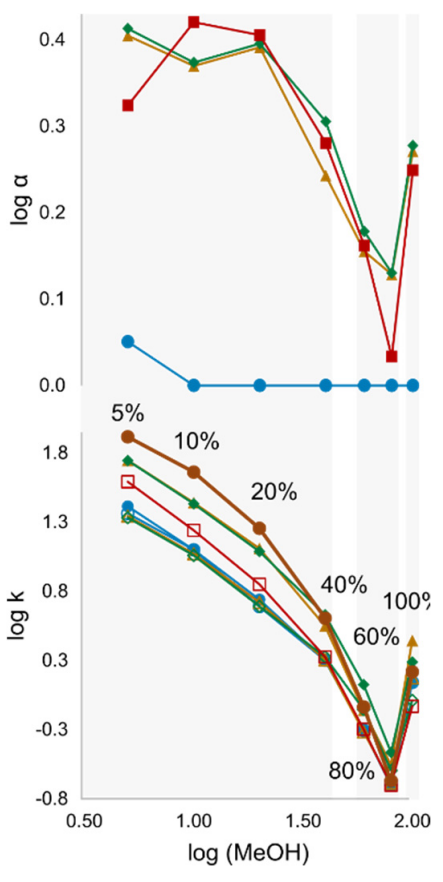

(b)

Figure 4. (a) Change in retention $\mathrm{k}$ for racemates of ketamine (blue), norketamine (orange), dehydronorketamine (green), and hydroxynorketamine (red) during transition from supercritical fluid chromatography (SFC) (5-40\% methanol) to enhanced-fluidity liquid chromatography (EFLC) $(40-80 \%)$, and ultimately HPLC mode (100\%). (b) The trend of decreasing enantioseparation $\log \alpha$ and $\log \mathrm{k}$ with rising modifier concentration continues to $80 \%$, at which point retention and separation increase and elution order is reversed. Column: Lux i-Amylose-3; modifier: methanol; additive: none. 


\subsection{Mobile Phase Optimization}

The use of $0 \%, 0.015 \%, 0.0375 \%$ or $0.15 \%$ of the basic additive $\mathrm{NH}_{3}$ (aqueous solution) reduced retention while improving enantioseparation $\alpha$ up to a concentration of $0.0375 \%$. Additional water content $(0 \%, 1 \%, 5 \%, 10 \%)$ neither improved nor impaired separation but helped to reduce retention times (Figure 5a). The exploitation of this effect was limited however by on-column pressure buildup which restricted the usage of $10 \% \mathrm{H}_{2} \mathrm{O}$ to low flow rates.

A back pressure increase from 100 to 175 bar benefited the $\alpha$ values for NK and DHNK, but exerted only minor effects on K and HNK. Similarly, the variation of flow rate (tested from 0.5 to $1.5 \mathrm{~mL} / \mathrm{min}$ ) shortened run times but had only a small impact on separation. The maximum pressure tolerance of the stationary phase ( 310 bar) limited the use of higher flow rates. Back pressure was therefore set to the minimal value of 100 bar in order to enable flow rates of $1.5 \mathrm{~mL} / \mathrm{min}$ in the final method. As illustrated in Figure 5, the optimization of additives, pressure, and flow rate exerted only minor effects and did not facilitate the desired result of separating rac-K.

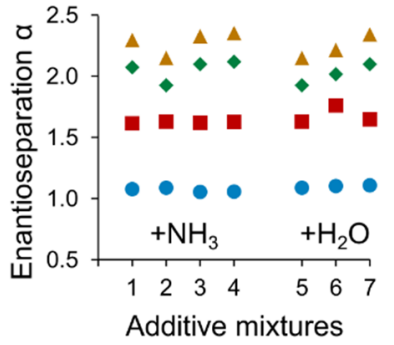

(a)

- Hydroxynorketamine (HNK)

- Dehydronorketamine (DHNK)

$\triangle$ Norketamine (NK)

- Ketamine $(\mathrm{K})$

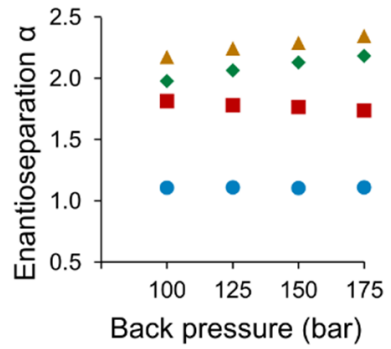

(b)

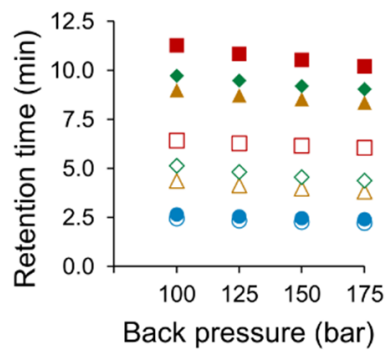

(e)

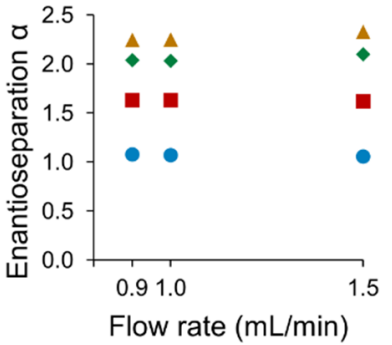

(c)

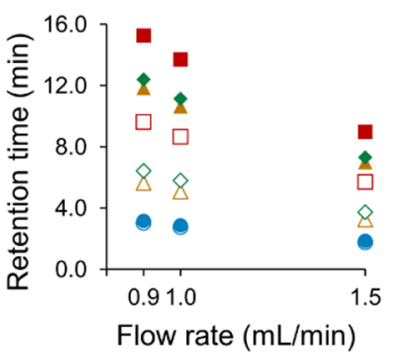

$(\mathbf{f})$

Figure 5. Effect of additives (a), back pressure (b), and flow rate (c) on the enantioseparation of ketamine metabolites (d), and the effects of back pressure (e) and flow rate (f) on retention times. Column: Lux i-Amylose-3; modifier: methanol; additive: $\mathrm{NH}_{3}, 0.015 \%$ (1), $0.0375 \%$ (2), $0.075 \%$ (3), $0.15 \%$ (4); $\mathrm{H}_{2} \mathrm{O}$, $0 \%(5), 1 \%(6), 5 \%(7)$.

\subsection{Temperature Effects}

The effect of temperature was investigated between 15 and $50{ }^{\circ} \mathrm{C}$. As predicted by Pirkle [31], lowering the column temperature to sub-ambient temperatures increased retention for all analytes and improved chiral separation by predominantly affecting the second eluting enantiomer (Figure 6). With the exception of the choice of stationary phase and modifier, the effects of temperature were more pronounced than those observed by the variation of additive, pressure, or flow rate. 

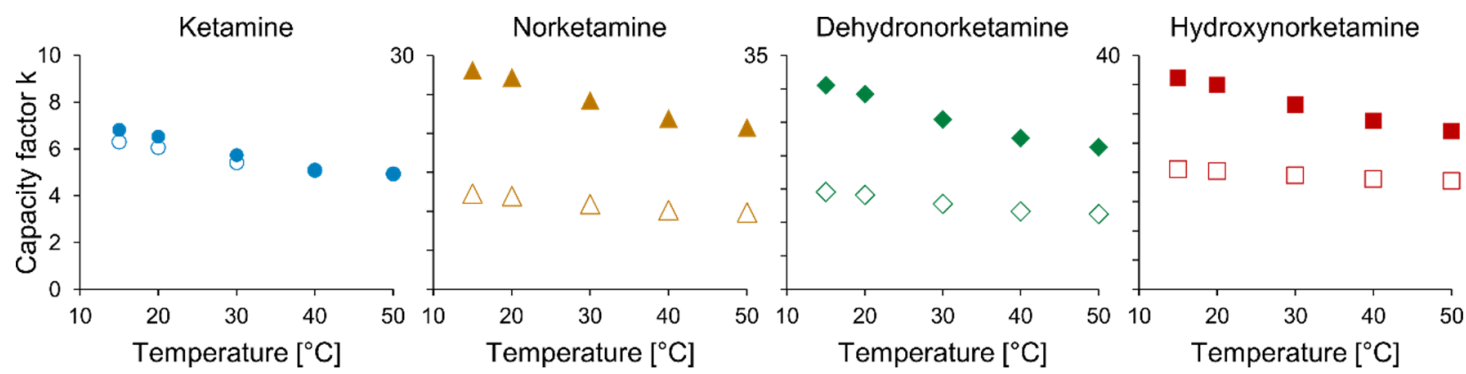

(a)
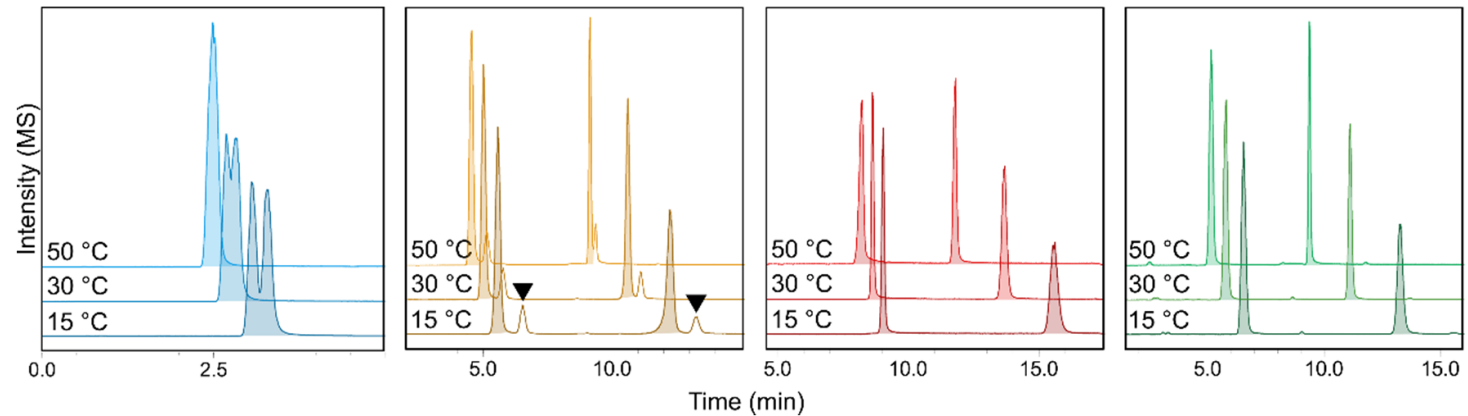

(b)

Figure 6. Effects of temperature variation on capacity factors k (a). Representative MS-chromatograms illustrate the increase in enantioresolution for all analytes at lower temperatures $(\mathbf{b})$. Note the isobaric interference of ${ }^{37} \mathrm{Cl}$-dehydronorketamine (black marks) in the mass trace of ${ }^{35} \mathrm{Cl}$-norketamine (orange), the chemoselective separation of which is also achieved by sub-ambient temperature subcritical fluid chromatography (SubFC). Column: Lux i-Amylose-3; modifier: methanol; additive: $\mathrm{NH}_{3}(0.0375 \%)$.

\subsection{Mobile Phase Homogeneity}

The supercritical point of pure $\mathrm{scCO}_{2}$ is situated at $31{ }^{\circ} \mathrm{C}$ and 74 bar, but the introduction of modifier and additives raises these parameters so that the term SFC paradoxically includes subcritical fluid chromatography [32]. Pirkle suggested the term SubFC for subcritical fluid chromatography to avoid confusion, but because sometimes SFC turns into SubFC unnoticed within a gradient elution, SFC and SubFC are most often not distinguished. SubFC, principally HPLC with $\mathrm{CO}_{2}$, retains many of the beneficial separation attributes of SFC as long as phase homogeneity is maintained to yield reproducible retention times. A 10-run reproducibility test was performed on all analytes at $15{ }^{\circ} \mathrm{C}$ in order to screen for variations in retention times due to phase separation. As shown in Table 3 , the relative standard deviation (RSD) of retention times varied between $0.4 \%(\mathrm{HNK})$ and $1.4 \%(\mathrm{~K})$, and thus was similar to alternative forms of SFC [28]. A representative chromatogram obtained by the final method can be seen in Figure 7.

Table 3. Variation of retention times Rt for racemic ketamine (K), norketamine (NK), dehydronorketamine (DHNK), and hydroxynorketamine (HNK) during consecutive separations $(n=10)$ with sub-ambient temperature subcritical fluid chromatography (SubFC). SD, standard deviation; RSD, relative standard deviation.

\begin{tabular}{ccc|cc|c}
\hline \multirow{2}{*}{ Analyte } & \multicolumn{2}{c|}{ First Eluting Enantiomer } & \multicolumn{2}{c|}{ Second Eluting Enantiomer } & \multirow{2}{*}{ Resolution } \\
\cline { 2 - 5 } & $\mathbf{R t} \pm$ SD (min) & RSD (\%) & Rt \pm SD (min) & RSD (\%) & Rs \\
\hline K & $2.466 \pm 0.028$ & 1.13 & $2.680 \pm 0.038$ & 1.44 & 1.33 \\
NK & $3.893 \pm 0.017$ & 0.45 & $6.793 \pm 0.072$ & 1.06 & 12.40 \\
DHNK & $4.281 \pm 0.022$ & 0.52 & $7.425 \pm 0.090$ & 1.25 & 16.42 \\
HNK & $4.956 \pm 0.021$ & 0.43 & $7.729 \pm 0.042$ & 0.54 & 13.04 \\
\hline
\end{tabular}




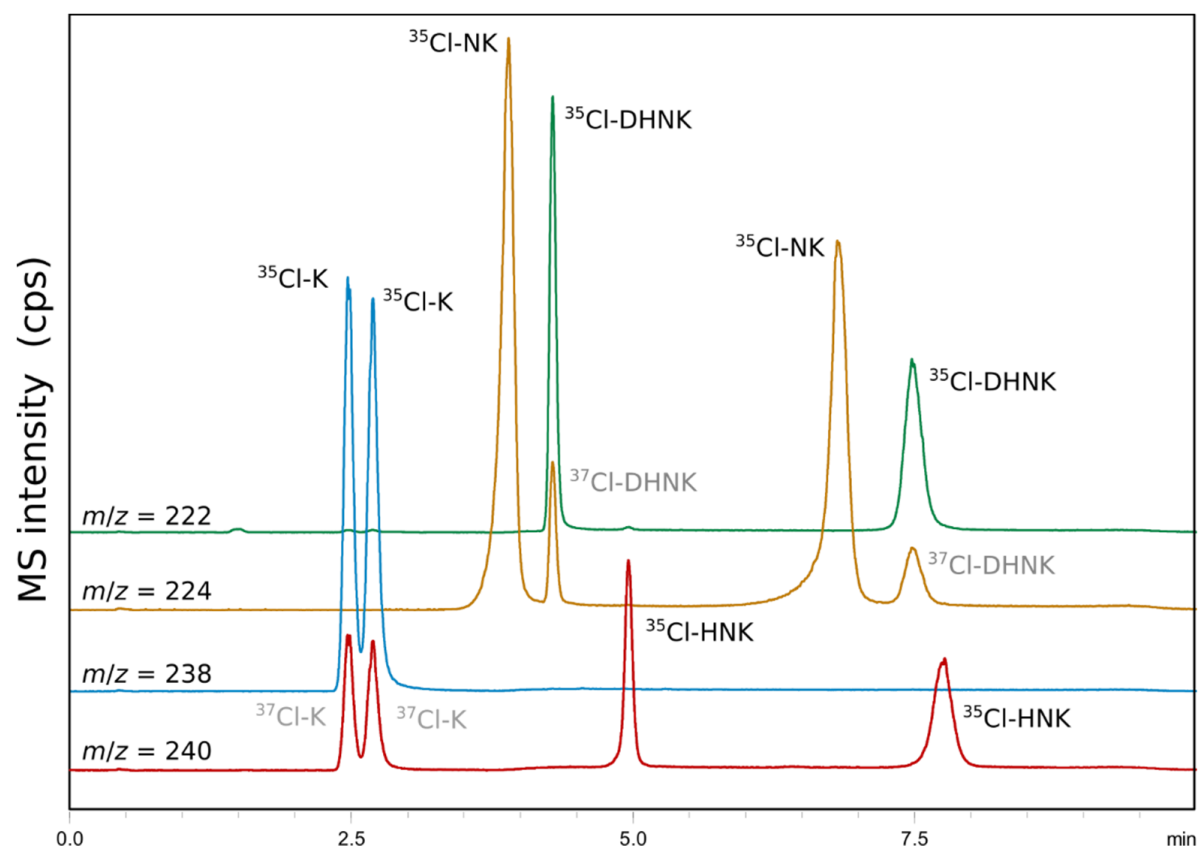

Figure 7. Representative chromatogram obtained after the optimization of the sub-ambient temperature subcritical fluid chromatography (SubFC) method for chemo- and enantio-selective separation of ketamine (K), norketamine (NK), dehydronorketamine (DHNK), and hydroxynorketamine (HNK). Note the isobaric interference of ${ }^{37} \mathrm{Cl}$-isotopic analytes between mass traces that differ in $\mathrm{m} / \mathrm{z} 2$, thus requiring chemo-selective separation even when using MS detection. Column: Lux i-Amylose-3; modifier: methanol; additives: $\mathrm{NH}_{3}(0.0375 \%), \mathrm{H}_{2} \mathrm{O}(5 \%)$; back pressure: 100 bar; temperature: $15{ }^{\circ} \mathrm{C}$.

\subsection{Application to Antidepressant Drug Formulations}

The direct injection of a rac-K infusion enabled the determination of the racemic nature of the antidepressant within as little as $3 \mathrm{~min}$ by sub-ambient temperature subcritical fluid chromatography (SubFC) and photodiode array (PDA) detection. Due to the stronger retention of demethylated metabolites, a gradient starting at $3.25 \mathrm{~min}$ was used in the final method. The change in mobile phase UV-absorption interfered with the PDA-detection of NK, DHNK and HNK, which required MS-detection. The enantiopurity of an S-HNK nasal spray formulated for research purposes was therefore analyzed by SubFC-MS. Pure (single peak at $5 \mathrm{~min}$ for HNK, $m / z 240$ ) and contaminated formulations ( $2 \%$, in analogy to K [33]) could be easily discriminated (Figure 8 ).
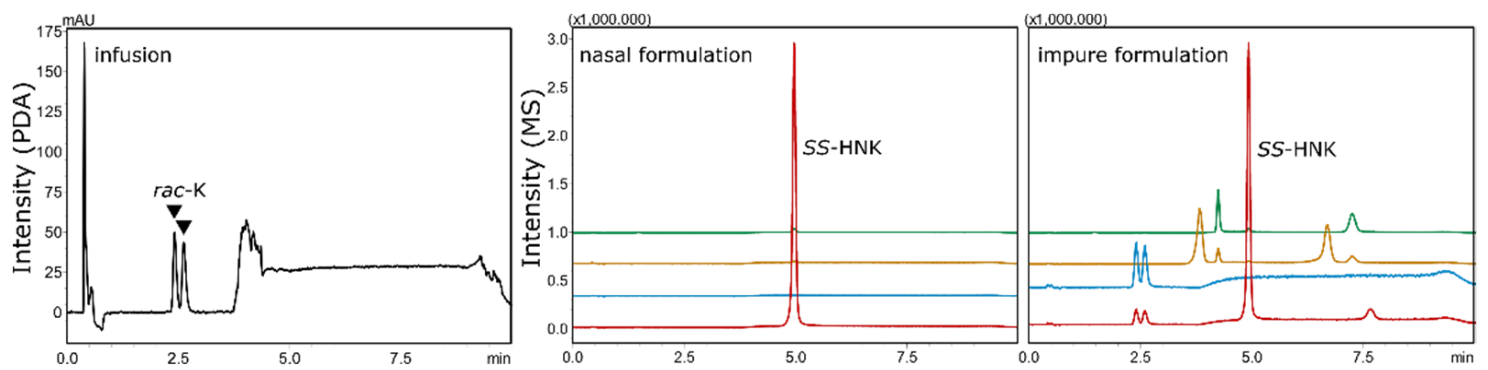

Figure 8. Quality control of a rac-K infusion using a PDA detector (SubFC-UV at $200 \mathrm{~nm}$ ) and a nasal spray formulation of pure and adulterated $(2 S, 6 S)$-hydroxynorketamine (SS-HNK) in combination with mass detection (SubFC-MS in SIM mode).

For formulations containing ingredients that were not deemed suitable for direct injection, supercritical fluid extraction (SFE) hyphenated to SubFC-MS was performed on adsorbed samples. K-, $\mathrm{NK}-$, and DHNK-formulations were found to be easily extractable using pure $\mathrm{scCO}_{2}$, whereas the more polar HNK is known to require the addition of polar additives for complete extraction (Figure 9) [34]. 


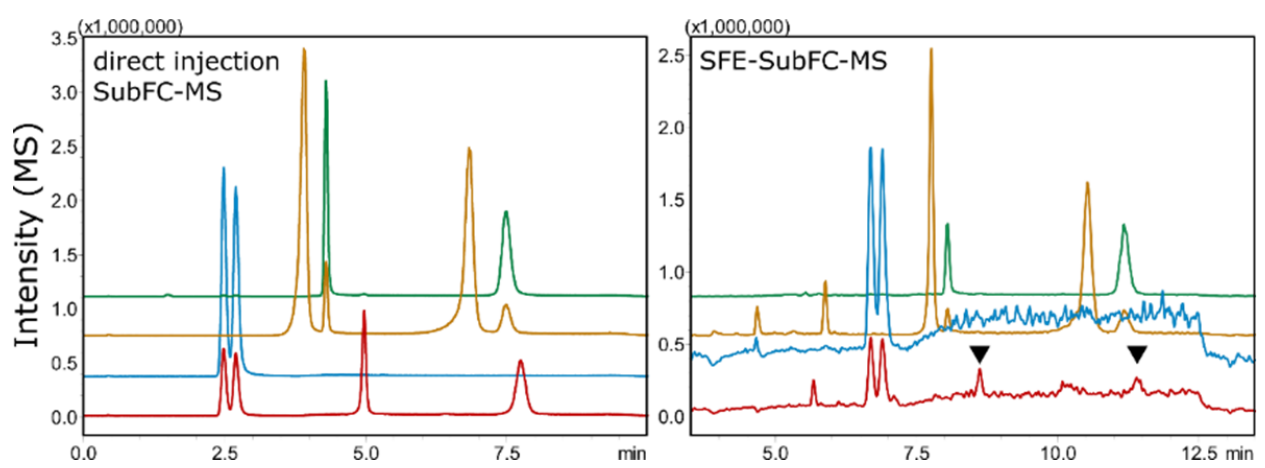

Figure 9. Comparison of direct injection SubFC-MS and online $\mathrm{scCO}_{2}$-extraction-chromatography SFE-SubFC-MS of ketamine (blue), norketamine (orange), dehydronorketamine (green), and hydroxynorketamine (red). While the former analytes are easily extracted, hydroxynorketamine (black marks) is more polar and is only incompletely extracted using pure $\mathrm{scCO}_{2}$.

\section{Discussion}

Although SFC separations on the latter CSP have been reported [35-37], to the best of our knowledge this is the first comparison involving i-Amylose-3. Our results suggest halogen- and hydrogen-bonding to be significant for chiral recognition of chlorinated analytes such as $\mathrm{K}$ and its metabolites on chlorinated polysaccharide-based CSPs, which is supported by previous observations concerning achiral chemo-selectivity of halogenated analytes on Amylose-2 [38].

As became clear during method development, the use of additives and the variation of pressure and flow rate showed only minor effects on resolution. Changes in temperature, however, significantly impacted chiral separation. Contrary to previous reports of peaks narrowing as temperature rises [22], we observed better peak shapes and chiral resolution as temperature declined with the best performance at sub-ambient temperatures $\left(15^{\circ} \mathrm{C}\right)$. Method development for SFC methods generally entails the screening of temperatures from $25-60{ }^{\circ} \mathrm{C}$ [39] and sometimes ambient temperatures [37,40], however, sub-ambient temperature working conditions, here tentatively termed SubFC, proved superior in the case of analytes that otherwise resisted chiral resolution (K). Indeed, while higher temperatures are known to affect the chiral recognition ability of polymeric CSPs through the induction of-often irreversible—conformational changes [41], lower temperatures may increase the rigidity of the polysaccharide back bone resulting in higher accessibility to the chiral ravines, within which enantio-selective hydrogen bonding is responsible for chiral recognition [42]. Our findings support the significance of hydrogen bonding in SFC mode at lower temperatures, and indicate higher performing yet reproducible results that will require further verification with a broader range of analytes and stationary phases.

The final separation method was chemo-selective to K, NK, DHNK, and HNK. The method exhibited enantio-selectivity for all metabolites. The separation of rac-K remained the most challenging enantiomer pair and although baseline separation was not achieved, resolution was higher than that of previous SFC methods, which allowed the evaluation of enantiomeric excess [19].

The application of SubFC-UV and SubFC-MS to pharmaceutical products demonstrated compatibility with the direct injection of aqueous formulations and online supercritical fluid extraction-supercritical fluid chromatography of adsorbed samples (which in our lab is used for testing for contamination/residues). As SFE has recently gained importance as a swift and safe offline extraction method for antioxidant [43], anti-metastatic [44], and bioactive pharmaceutical compounds [45], compatibility with online SFE may be considered indicative of SubFCs' potential for quality control. 


\section{Materials and Methods}

\subsection{Chemicals}

$\mathrm{CO}_{2}$ (99.995\% purity) was provided by Air Liquide (Duesseldorf, Germany). Modifiers and additives were obtained in LC-MS grade from VWR (Leuven, Belgium). Lux Amylose-2 (150 × $4.6 \mathrm{~mm}$, $5 \mu \mathrm{m})$, i-Amylose-3 $(150 \times 2.0 \mathrm{~mm}, 3 \mu \mathrm{m})$, and i-Cellulose-5 $(100 \times 3.0 \mathrm{~mm}, 3 \mu \mathrm{m})$ were purchased from Phenomenex (Aschaffenburg, Germany). $S$-/R-ketamine ( $S$-/R-K), $S$-/R-norketamine $(S-/ R-N K)$, and $S$-/R-dehydronorketamine $(S-/ R$-DHNK) were acquired as hydrochlorides from Sigma-Aldrich (Steinheim, Germany), except for $(2 R, 6 R)$ - and $(2 S, 6 S)$-hydroxynorketamine (SS-/RR-HNK) which were kindly provided by the National Center for Advancing Translational Sciences (Rockville, Maryland, USA). Stock solutions were prepared in methanol and stored at $-20{ }^{\circ} \mathrm{C}$. Working solutions were prepared weekly and stored at $4{ }^{\circ} \mathrm{C}$.

\subsection{Instruments}

Data acquisition was realized using a Nexera SFE-SFC/UHPLC switching system (Shimadzu Corporation, Kyoto, Japan) shown in Figure 10. The pumping system consisted of three units (one LC-30ADSF for liquid $\mathrm{CO}_{2}$ (A) and two LC-20ADXR for modifier (B) and make-up (C) delivery). Samples were introduced either directly (autosampler SIL-30AC) or by online supercritical fluid extraction (SFE-30A auto extractor equipped with $0.2 \mathrm{~mL}$ extraction vessels). The system consisted further of a column thermostat (CTO-20AC), a degasser (DGU-20A5R), a communications module (CBM-20A), and two back pressure regulators BPR A and B (SFC-30A). Only BPR A was used for the dynamic regulation of back pressure; the splitting function of BPR B (on-column/waste split for the analysis of highly concentrated biomatrices) was not used. The PDA detector (SPD-M20A) was set to $200 \mathrm{~nm}$. Optimization of electrospray ionization-single quadrupole mass spectrometry (LCMS-2020) yielded $0.1 \mathrm{~mL} / \mathrm{min}$ make up (2-propanol), $1.5 \mathrm{~L} / \mathrm{min}$ nebulizing and $12 \mathrm{~L} / \mathrm{min}$ drying gas $\left(\mathrm{N}_{2}\right) ; 250{ }^{\circ} \mathrm{C}$ desolvation line, $300{ }^{\circ} \mathrm{C}$ heat block, and $350{ }^{\circ} \mathrm{C}$ interface temperature; $4.5 \mathrm{kV}$ interface voltage. SIM: $m / z 238$ (S-/R-K), 224 (S-/R-NK), 222 (S-/R-DHNK), and 240 (SS-/RR-HNK). The system was controlled by Shimadzu LabSolution software (Version 5.91, Kyoto, Japan).

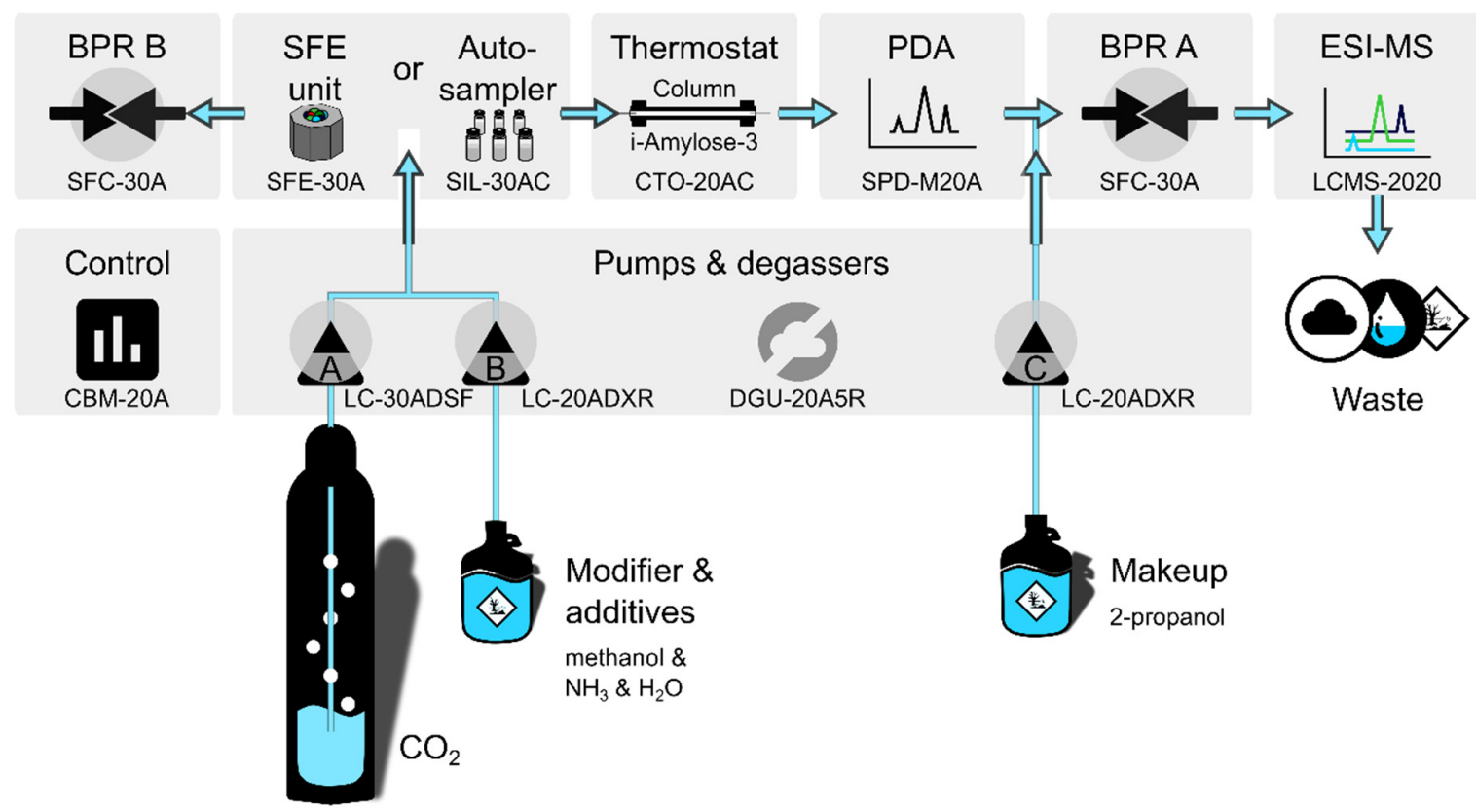

Figure 10. Schematic setup of the super-/subcritical fluid chromatograph. SFE, supercritical fluid extraction; PDA, photo diode array detector; BPR, back pressure regulator; ESI-MS, electrospray ionization-mass spectrometry. 


\subsection{Chromatographic Parameters}

Unless stated otherwise, the parameters of the final method apply. Stationary phase: i-Amylose-3 $(150 \times 2.0 \mathrm{~mm}, 3 \mu \mathrm{m})$. Mobile phase $(\mathrm{A})$ : supercritical $\mathrm{CO}_{2} ;$ modifier $(\mathrm{B})$ : methanol; additives (as a volumetric percentage of $\mathrm{B}): \mathrm{NH}_{3}(0.0375 \%)$ and $\mathrm{H}_{2} \mathrm{O}(5 \%)$. Gradient (B): 0-3.0 min (8\%), 3.0-3.25 min (8-25\%), 3.25-8.5 $\mathrm{min}(25 \%), 8.5-9.0 \mathrm{~min}(25-8 \%), 9.0-10.0 \mathrm{~min}(8 \%)$. Flow rate: $1.5 \mathrm{~mL} / \mathrm{min}$. BPR: 100 bar. Temperature: $15^{\circ} \mathrm{C}$.

Stationary phases were screened using methanol or 2-propanol without an additive in gradient mode (Section 4.3). Flow rate was adjusted to reflect differences in column inner diameter (for details, see supplementary information Figure S1).

Since mobile phase viscosity increased with rising $\mathrm{B} \%$, total flow rates had to be adjusted during transition from SFC (5\%, $2.5 \mathrm{~mL} / \mathrm{min} ; 10 \%, 2.0 \mathrm{~mL} / \mathrm{min} ; 20 \%, 1.5 \mathrm{~mL} / \mathrm{min} ; 40 \%, 1 \mathrm{~mL} / \mathrm{min}$ ) to EFLC $(60 \%, 0.6 \mathrm{~mL} / \mathrm{min} ; 80 \%, 0.5 \mathrm{~mL} / \mathrm{min})$ and ultimately $\mathrm{HPLC}(100 \%, 2.5 \mathrm{~mL} / \mathrm{min})$. No additive was used in this experiment in order to prevent the damage of the stationary phase in HPLC mode, which-even when using immobilized materials - is less resistant to basic than to acidic $\mathrm{pH}$.

Additive studies were performed in methanol due to the superior resolution in this modifier. $\mathrm{NH}_{3}$ (25\% aqueous solution) was tested at the following concentrations: $0.015 \%, 0.0375 \%, 0.075 \%$, and $0.150 \%$. Values are given as percent volume ratio, e.g., in order to obtain a modifier solution containing $0.015 \% \mathrm{NH}_{3}, 30 \mu \mathrm{L}$ of aqueous $\mathrm{NH}_{3}$ was added to $50 \mathrm{~mL}$ of methanol, stirred, and sonicated for $5 \mathrm{~min}$. Effects of additional water were investigated by adding 1\%, 5\%, or 10\% of water to a solution of methanol containing $0.0375 \% \mathrm{NH}_{3}$.

\subsection{Molecular Modelling}

All calculations were performed using the Molecular Operating Environment (MOE) software suite (version 2019.01) [46]. For each column material, a hexameric strand was built of customized D-glucopyranose monomers by replacing the hydroxyl groups with the corresponding substituted phenyl carbamates in positions 2, 3 and 6. AMBER force field parameters were applied and the geometry was optimized using LowModeMD [47] to remove initial strains.

The 2D structures were prepared from SMILES, converted to 3D, energetically minimized and protonated according to a $\mathrm{pH}$ value of 5 [48]. AM1-BCC charges and AMBER force field parameters were applied prior to molecular docking.

Since no explicit binding site can be defined, a blind docking approach was utilized, where the whole hexamer is used as the receptor structure. Docking was performed in two steps. We selected 100 poses using flexible ligands, the Triangle Matcher placement method, and London dG scoring. A total of 25 poses for each ligand were refined, while keeping the oligomers rigid. All final poses were visually inspected afterwards.

Retention factors

$$
\mathrm{k}=\left(\mathrm{t}_{\mathrm{R}}-\mathrm{t}_{0}\right) / \mathrm{t}_{0}
$$

were based on void times $t_{0}$ estimated from the earliest baseline perturbation as described by Zhu et al. [49]. Resolution

$$
R_{s}=\left(1.18 \times\left(t_{R 1}-t_{R 2}\right)\right) /\left(w_{h 1}+w_{h 2}\right)
$$

was calculated according to the European Pharmacopoeia from the difference of retention and the sum of peak width at half-height $\left(\mathrm{w}_{\mathrm{h}}\right)$ [50].

\subsection{Application to Pharmaceutical Formulations}

Infusions of $\mathrm{rac}-\mathrm{K}$ were reproduced according to clinical use $(0.5 \mathrm{mg} / \mathrm{mL}$ in isotonic $\mathrm{NaCl}$-solution) and an experimental nasal spray formulation for non-human application containing S-HNK $(1 \mathrm{mg} / \mathrm{mL})$ was diluted 1:1000 prior to direct injection (supplementary information Figure S2). A master mix containing racemates of $\mathrm{K}, \mathrm{NK}, \mathrm{DHNK}$, and $\mathrm{HNK}$ was prepared identically and either injected directly 
(for comparison) or adsorbed onto calcined $\mathrm{SiO}_{2} /$ quartz (isolute ${ }^{\circledR} \mathrm{HM}-\mathrm{N}$ ) and dried for $1 \mathrm{~h}$ at $40^{\circ} \mathrm{C}$. Supercritical fluid extraction was performed statically for $3.0 \mathrm{~min}$ and dynamically for $0.5 \mathrm{~min}$ with pure $\mathrm{scCO}_{2}$. The extract was directly introduced into the chromatographic system but was trapped at the column head, as elution did not proceed in the absence of a modifier. SubFC was performed as described above. Details of the extraction program are given in the supplementary information (Figure S3).

Supplementary Materials: The following are available online. Figure S1: System settings (column screening); Figure S2: System settings (SubFC); Figure S3: System settings (SFE- SubFC).

Author Contributions: Conceptualization, R.K.H. and S.K.; methodology, supervision and writing-original draft preparation, R.K.H.; investigation, R.K.H., F.P. and M.H.; software, formal analysis and data curation, L.S.; visualization, R.K.H. and L.S.; project administration, resources, funding acquisition, writing-review and editing, A.L.

Funding: The APC was funded by the DFG (German Research Foundation, 393148499) and the Open Access Publication Fund of the University of Greifswald.

Acknowledgments: We thank Tzvetkov and Oswald for kindly providing standards of $R$ - and $S$-norketamine and dehydronorketamine. The analytical standards for (2S,6S)-hydroxynorktamine (NCGC00373033) and $(2 R, 6 R)$-hydroxynorketamine (NCGC00373033) were provided by the National Center for Advancing Translational Sciences (NCATS), National Institutes of Health.

Conflicts of Interest: The authors declare no conflict of interest.

\section{References}

1. Ketamine Nasal Spray Medication for Treatment-Resistant Depression. Available online: https://www.fda.gov/news-events/press-announcements/fda-approves-new-nasal-spray-medicationtreatment-resistant-depression-available-only-certified (accessed on 30 April 2019).

2. Zanos, P.; Moaddel, R.; Morris, P.J.; Riggs, L.M.; Highland, J.N.; Georgiou, P.; Pereira, E.F.R.; Albuquerque, E.X.; Thomas, C.J.; Zarate, C.A.; et al. Ketamine and Ketamine Metabolite Pharmacology: Insights into Therapeutic Mechanisms. Pharmacol. Rev. 2018, 70, 621-660. [CrossRef] [PubMed]

3. Grunebaum, M.F.; Ellis, S.P.; Keilp, J.G.; Moitra, V.K.; Cooper, T.B.; Marver, J.E.; Burke, A.K.; Milak, M.S.; Sublette, M.E.; Oquendo, M.A.; et al. Ketamine versus midazolam in bipolar depression with suicidal thoughts: A pilot midazolam-controlled randomized clinical trial. Bipolar Disord. 2017, 19, 176-183. [CrossRef] [PubMed]

4. $\quad$ Aust, S.; Gärtner, M.; Basso, L.; Otte, C.; Wingenfeld, K.; Chae, W.R.; Heuser-Collier, I.; Regen, F.; Cosma, N.C.; van Hall, F.; et al. Anxiety during ketamine infusions is associated with negative treatment responses in major depressive disorder. Eur. Neuropsychopharmacol. 2019, 29, 529-538. [CrossRef]

5. Cusin, C. Ketamine as a Rapid Antidepressant. In The Massachusetts General Hospital Guide to Depression; Shapero, B.G., Mischoulon, D., Cusin, C., Eds.; Springer International Publishing: Cham, New York City, NY, USA, 2019; pp. 139-145, ISBN 978-3-319-97240-4.

6. Keiser, M.; Hasan, M.; Oswald, S. Affinity of Ketamine to Clinically Relevant Transporters. Mol. Pharm. 2018, 15, 326-331. [CrossRef]

7. Naidoo, V.; Mdanda, S.; Ntshangase, S.; Naicker, T.; Kruger, H.G.; Govender, T.; Naidoo, P.; Baijnath, S. Brain penetration of ketamine: Intranasal delivery vs. parenteral routes of administraion. J. Psychiatr. Res. 2019, 112, 7-11. [CrossRef]

8. Li, W.; Liu, J.; Fan, M.; Li, Z.; Chen, Y.; Zhang, G.; Huang, Z.; Zhang, L. Scale-Up Synthesis and Identification of GLYX-13, a NMDAR Glycine-Site Partial Agonist for the Treatment of Major Depressive Disorder. Molecules 2018, 23, 996. [CrossRef] [PubMed]

9. Suzuki, K.; Nosyreva, E.; Hunt, K.W.; Kavalali, E.T.; Monteggia, L.M. Effects of a ketamine metabolite on synaptic NMDAR function. Nature 2017, 546, E1-E3. [CrossRef]

10. Zanos, P.; Moaddel, R.; Morris, P.J.; Georgiou, P.; Fischell, J.; Elmer, G.I.; Alkondon, M.; Yuan, P.; Pribut, H.J.; Singh, N.S.; et al. NMDAR inhibition-independent antidepressant actions of ketamine metabolites. Nature 2016, 533, 481-486. [CrossRef] [PubMed] 
11. Yang, Y.; Cui, Y.; Sang, K.; Dong, Y.; Ni, Z.; Ma, S.; Hu, H. Ketamine blocks bursting in the lateral habenula to rapidly relieve depression. Nature 2018, 554, 317-322. [CrossRef]

12. Yang, C.; Kobayashi, S.; Nakao, K.; Dong, C.; Han, M.; Qu, Y.; Ren, Q.; Zhang, J.; Ma, M.; Toki, H.; et al. AMPA Receptor Activation-Independent Antidepressant Actions of Ketamine Metabolite (S)-Norketamine. Biol. Psychiatry 2018, 84, 591-600. [CrossRef]

13. Pham, T.H.; Gardier, A.M. Fast-acting antidepressant activity of ketamine: highlights on brain serotonin, glutamate, and GABA neurotransmission in preclinical studies. Pharmacol. Ther. 2019. [CrossRef] [PubMed]

14. Lumsden, E.W.; Troppoli, T.A.; Myers, S.J.; Zanos, P.; Aracava, Y.; Kehr, J.; Lovett, J.; Kim, S.; Wang, F.-H.; Schmidt, S.; et al. Antidepressant-relevant concentrations of the ketamine metabolite (2R,6R)-hydroxynorketamine do not block NMDA receptor function. Proc. Natl. Acad. Sci. USA 2019, 116, 5160-5169. [CrossRef] [PubMed]

15. Fukumoto, K.; Fogaça, M.V.; Liu, R.-J.; Duman, C.; Kato, T.; Li, X.-Y.; Duman, R.S. Activity-dependent brain-derived neurotrophic factor signaling is required for the antidepressant actions of (2R,6R)-hydroxynorketamine. Proc. Natl. Acad. Sci. USA 2019, 116, 297-302. [CrossRef]

16. Hicks, M.B.; Farrell, W.; Aurigemma, C.; Lehmann, L.; Weisel, L.; Nadeau, K.; Lee, H.; Moraff, C.; Wong, M.; Huang, Y.; et al. Making the move towards modernized greener separations: introduction of the analytical method greenness score (AMGS) calculator. Green Chem. 2019, 21, 1816-1826. [CrossRef]

17. Rossi, D.; Tarantino, M.; Rossino, G.; Rui, M.; Juza, M.; Collina, S. Approaches for multi-gram scale isolation of enantiomers for drug discovery. Expert Opin. Drug Discov. 2017, 12, 1253-1269. [CrossRef]

18. Pilařová, V.; Plachká, K.; Khalikova, M.A.; Svec, F.; Nováková, L. Recent developments in supercritical fluid chromatography-Mass spectrometry: Is it a viable option for analysis of complex samples? Trends Anal. Chem. 2019, 112, 212-225. [CrossRef]

19. Fassauer, G.M.; Hofstetter, R.; Hasan, M.; Oswald, S.; Modeß, C.; Siegmund, W.; Link, A. Ketamine metabolites with antidepressant effects: Fast, economical, and eco-friendly enantioselective separation based on supercritical-fluid chromatography (SFC) and single quadrupole MS detection. J. Pharm. Biomed. Anal. 2017, 146, 410-419. [CrossRef] [PubMed]

20. Hasan, M.; Hofstetter, R.; Fassauer, G.M.; Link, A.; Siegmund, W.; Oswald, S. Quantitative chiral and achiral determination of ketamine and its metabolites by LC-MS/MS in human serum, urine and fecal samples. J. Pharm. Biomed. Anal. 2017, 139, 87-97. [CrossRef] [PubMed]

21. Teixeira, J.; Tiritan, M.E.; Pinto, M.M.M.; Fernandes, C. Chiral Stationary Phases for Liquid Chromatography: Recent Developments. Molecules 2019, 24, 865. [CrossRef]

22. Chen, L.; Dean, B.; Liang, X. Evaluation of polysaccharide-based chiral stationary phases in modern SFC-MS/MS for enantioselective bioanalysis. Bioanalysis 2019, 11, 251-266. [CrossRef] [PubMed]

23. Peluso, P.; Dessì, A.; Dallocchio, R.; Mamane, V.; Cossu, S. Recent studies of docking and molecular dynamics simulation for liquid-phase enantioseparations. Electrophoresis 2019, 0, 1-16. [CrossRef] [PubMed]

24. Tarafder, A. Metamorphosis of supercritical fluid chromatography to SFC: An Overview. Trends Anal. Chem. 2016, 81, 3-10. [CrossRef]

25. Otsubo, M.; Motono, T.; Kitagawa, S.; Ohtani, H. Effect of Column Structure on Separation Efficiency in Low-Temperature HPLC Using Pure Liquid Carbon Dioxide as the Mobile Phase. Chromatography 2017, 38, 31-37. [CrossRef]

26. Bennett, R.; Biba, M.; Liu, J.; Haidar Ahmad, I.A.; Hicks, M.B.; Regalado, E.L. Enhanced fluidity liquid chromatography: A guide to scaling up from analytical to preparative separations. J. Chromatogr. A 2019, 1595, 190-198. [CrossRef] [PubMed]

27. Bennett, R.; Olesik, S.V. Enhanced fluidity liquid chromatography of inulin fructans using ternary solvent strength and selectivity gradients. Anal. Chim. Acta 2018, 999, 161-168. [CrossRef] [PubMed]

28. Bennett, R.; Olesik, S.V. Protein separations using enhanced-fluidity liquid chromatography. J. Chromatogr. A 2017, 1523, 257-264. [CrossRef] [PubMed]

29. Khater, S.; Lozac'h, M.-A.; Adam, I.; Francotte, E.; West, C. Comparison of liquid and supercritical fluid chromatography mobile phases for enantioselective separations on polysaccharide stationary phases. J. Chromatogr. A 2016, 1467, 463-472. [CrossRef] 
30. West, C.; Konjaria, M.-L.; Shashviashvili, N.; Lemasson, E.; Bonnet, P.; Kakava, R.; Volonterio, A.; Chankvetadze, B. Enantioseparation of novel chiral sulfoxides on chlorinated polysaccharide stationary phases in supercritical fluid chromatography. J. Chromatogr. A 2017, 1499, 174-182. [CrossRef]

31. Pirkle, W.H.; Wolf, C. Enantioseparations by subcritical fluid chromatography at cryogenic temperatures. J. Chromatogr. A 1997, 785, 173-178.

32. Tyśkiewicz, K.; Gieysztor, R.; Maziarczyk, I.; Hodurek, P.; Rój, E.; Skalicka-Woźniak, K. Supercritical Fluid Chromatography with Photodiode Array Detection in the Determination of Fat-Soluble Vitamins in Hemp Seed Oil and Waste Fish Oil. Molecules 2018, 23, 1131. [CrossRef]

33. Esketamine hydrochloride. In European Pharmacopoeia 9.3; EDQM: Strasbourg, France, 2017; pp. $4895-4896$.

34. Hofstetter, R.; Fassauer, G.M.; Link, A. Supercritical fluid extraction (SFE) of ketamine metabolites from dried urine and on-line quantification by supercritical fluid chromatography and single mass detection (on-line SFE-SFC-MS). J. Chromatogr. B 2018, 1076, 77-83. [CrossRef]

35. Dascalu, A.-E.; Ghinet, A.; Billamboz, M.; Lipka, E. Performance comparison of chlorinated chiral stationary phases in supercritical fluid chromatography for separation of selected pyrrolidone derivatives. J. Pharm. Anal. 2019. [CrossRef]

36. Lipka, E.; Dascalu, A.-E.; Messara, Y.; Tsutsqiridze, E.; Farkas, T.; Chankvetadze, B. Separation of enantiomers of native amino acids with polysaccharide-based chiral columns in supercritical fluid chromatography. J. Chromatogr. A 2019, 1585, 207-212. [CrossRef]

37. Orosz, T.; Bajtai, A.; Minh Le, T.; Tanács, D.; Szakonyi, Z.; Fülöp, F.; Péter, A.; Ilisz, I. Chiral high-performance liquid and supercritical fluid chromatographic enantioseparations of limonene-based bicyclic aminoalcohols and aminodiols on polysaccharide-based chiral stationary phases. Biomed. Chromatogr. 2019, 33, e4517. [CrossRef]

38. Hofstetter, R.K.; Hasan, M.; Fassauer, G.M.; Bock, C.; Surur, A.S.; Behnisch, S.; Grathwol, C.W.; Potlitz, F.; Oergel, T.; Siegmund, W.; et al. Simultaneous quantification of acidic and basic flupirtine metabolites by supercritical fluid chromatography according to European Medicines Agency validation. J. Chromatogr. A 2019. (In press) [CrossRef]

39. Harps, L.C.; Joseph, J.F.; Parr, M.K. SFC for chiral separations in bioanalysis. J. Pharm. Biomed. Anal. 2019, 162, 47-59. [CrossRef] [PubMed]

40. Kadkhodaei, K.; Forcher, L.; Schmid, M.G. Separation of enantiomers of new psychoactive substances by high-performance liquid chromatography. J. Sep. Sci. 2018, 41, 1274-1286. [CrossRef] [PubMed]

41. Ikai, T.; Okamoto, Y. Structure Control of Polysaccharide Derivatives for Efficient Separation of Enantiomers by Chromatography. Chem. Rev. 2009, 109, 6077-6101. [CrossRef]

42. Matarashvili, I.; Ghughunishvili, D.; Chankvetadze, L.; Takaishvili, N.; Khatiashvili, T.; Tsintsadze, M.; Farkas, T.; Bezhan, F. Separation of enantiomers of chiral weak acids with polysaccharide-based chiral columns and aqueous-organic mobile phases in high-performance liquid chromatography: Typical reversed-phase behavior? J. Chromatogr. A 2017, 1483, 86-92. [CrossRef] [PubMed]

43. Wang, C.; Duan, Z.; Fan, L.; Li, J. Supercritical $\mathrm{CO}_{2}$ Fluid Extraction of Elaeagnus mollis Diels Seed Oil and Its Antioxidant Ability. Molecules 2019, 24, 911. [CrossRef]

44. Wang, H.-L.; Chang, J.-C.; Fang, L.-W.; Hsu, H.-F.; Lee, L.-C.; Yang, J.-F.; Liang, M.-T.; Hsiao, P.-C.; Wang, C.-P.; Wang, S.-W.; et al. Bulnesia sarmientoi Supercritical Fluid Extract Exhibits Necroptotic Effects and Anti-Metastatic Activity on Lung Cancer Cells. Molecules 2018, 23, 3304. [CrossRef]

45. Molino, A.; Larocca, V.; Di Sanzo, G.; Martino, M.; Casella, P.; Marino, T.; Karatza, D.; Musmarra, D. Extraction of Bioactive Compounds Using Supercritical Carbon Dioxide. Molecules 2019, 24, 782. [CrossRef] [PubMed]

46. Molecular Operating Environment (MOE) Software Suite; Version 2019.01; Chemical Computing Group, ULC: Montreal, QC, Canada, 2019.

47. Labute, P. LowModeMD-Implicit low-mode velocity filtering applied to conformational search of macrocycles and protein loops. J. Chem. Inf. Model. 2010, 50, 792-800. [CrossRef] [PubMed]

48. West, C.; Melin, J.; Ansouri, H.; Mengue Metogo, M. Unravelling the effects of mobile phase additives in supercritical fluid chromatography. Part I: Polarity and acidity of the mobile phase. J. Chromatogr. A 2017, 1492, 136-143. [CrossRef] [PubMed] 
49. Zhu, B.; Zhao, F.; Yu, J.; Wang, Z.; Song, Y.; Li, Q. Chiral separation and a molecular modeling study of eight azole antifungals on the cellulose tris(3,5-dichlorophenylcarbamate) chiral stationary phase. New J. Chem. 2018, 42, 13421-13429. [CrossRef]

50. Chromatographic Separation Techniques. In European Pharmacopoeia 9.8; EDQM: Strasbourg, France, 2019; pp. 4286-4293.

Sample Availability: Samples of the compounds are not available from the authors.

(C) 2019 by the authors. Licensee MDPI, Basel, Switzerland. This article is an open access article distributed under the terms and conditions of the Creative Commons Attribution (CC BY) license (http://creativecommons.org/licenses/by/4.0/). 